\title{
Biomechanical analysis of titanium plate systems in mandibular condyle fractures. A systematized literature review ${ }^{1}$
}

\author{
Análise biomecânica de sistemas de placas de titânio em fraturas de côndilo mandibular. \\ Uma revisão sistematizada da literatura
}

\author{
Fábio Wildson Gurgel Costa ${ }^{\mathrm{I}}$, Marcelo Ferraro Bezerra ${ }^{\mathrm{II}}$, Thyciana Rodrigues Ribeiro ${ }^{\mathrm{III}}$, Ernest Cavalcante Pouchain ${ }^{\mathrm{IV}}$, Vicente \\ de Paulo Aragão Sabóiav, Eduardo Costa Studart Soares ${ }^{\mathrm{VI}}$
}

\begin{abstract}
IAssistant Professor, Division of Stomatology, UFC, Sobral Campus, Fortaleza-CE, Brazil. Responsible for conception, design, intellectual and scientific content of the study; acquisition and interpretation of data; manuscript writing.

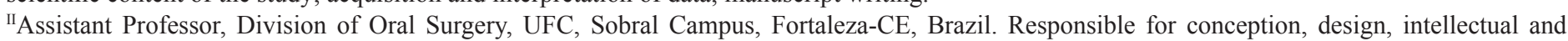
scientific content of the study, manuscript writing.

IIIDDS, MS, PhD degree, Department of Clinical Dentistry, UFC, Fortaleza-CE, Brazil. Responsible for conception, design, intellectual and scientific content of the study, manuscript writing.

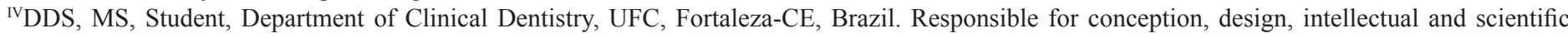
content of the study, manuscript writing.

${ }^{\mathrm{v}} \mathrm{PhD}$, Associate Professor, Division of Dentistry, UFC, Fortaleza-CE, Brazil. Responsible for conception, design, intellectual and scientific content of the study; manuscript writing; critical revision.

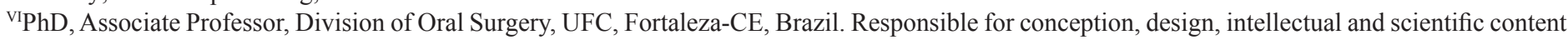
of the study; manuscript writing; critical revision.
\end{abstract}

\begin{abstract}
PURPOSE: To conduct a systematized review of the literature about the main methodologies used to evaluate the biomechanical fixation systems with titanium plates in fractures of the mandibular condyle.

METHODS: A systematized review of literature was performed in the electronic databases PubMed, EMBASE, LILACS and MEDLINE without restriction of the publication date. The eligibility criteria were laboratory studies involving mandibular condyle fractures, studies using titanium plates, biomechanical studies, in vitro and computational studies involving the finite element method (FEM).

RESULTS: Eleven articles that met the eligibility criteria were selected, including seven articles involving in vitro studies and four studies with biomechanical analysis by using FEM.

CONCLUSION: Although few articles have used the finite element method, the results of in vitro studies were similar to those found in computational studies, regarding to the stable use of two titanium miniplates.
\end{abstract}

Key words: Mandibular Condyle. Fracture Fixation. Titanium. Biomechanics. Review.

\section{RESUMO}

OBJETIVO: Realizar uma revisão sistematizada da literatura sobre as principais metodologias empregadas na avaliação biomecânica de sistemas de fixação com placas de titânio em fraturas de côndilo mandibular.

MÉTODOS: Foi realizada uma revisão sistematizada da literatura nas bases de dados eletrônicas PubMed, EMBASE, LILACS e MEDLINE sem restrição quanto à data de publicação. Os critérios de elegibilidade foram estudos laboratoriais envolvendo fraturas de côndilo mandibular, estudos utilizando placas de titânio, estudos biomecânicos, estudos in vitro e estudos computacionais envolvendo o método de elementos finitos (MEF).

RESULTADOS: Foram selecionados 11 artigos que se enquadraram nos critérios de elegibilidade, incluindo sete artigos envolvendo estudos in vitro e quatro utilizando análise biomecânica através do MEF.

CONCLUSÃO: Embora poucos artigos tenham utilizado o método de elementos finitos, os resultados das pesquisas in vitro assemelhamse aos encontrados nos estudos computacionais, com relação ao uso estável de duas miniplacas de titânio.

Descritores: Côndilo Mandibular. Fixação de Fratura. Titânio. Biomecânica. Revisão. 


\section{Introduction}

Craniomaxillofacial trauma represents severe health hazards in a significant proportion of patients throughout the world, varying in type, severity and etiology according to the studied population ${ }^{1}$. Such injuries may occur alone or in association with other relevant damage in the brain, spine and other parts of the skeleton ${ }^{2}$. In this context, jaw is one of the facial bones most commonly fractured, representing between 17.5 and $52 \%$ of cases in the craniomaxillofacial region ${ }^{3}$. Anatomically, the main mandibular regions affected by fractures that have been reported, in decreasing order of occurrence, are angle, condyle, parasymphysis, body, symphysis, ascendant ramus and coronoid process $^{4}$.

Mandibular condyle fractures represent 25-35\% of all mandibular fractures ${ }^{5}$, being considered one of the most controversial fractures concerning to diagnosis and treatment ${ }^{6}$. Although choosing the best treatment still remains under discussion $^{7}$, the indication for open reduction and fixation of the fractured segments with the use of titanium plates and screws has been reported by several authors ${ }^{8-13}$.

Different osteosynthesis techniques have been used against these fractures aiming the achievement of satisfactory results ${ }^{14}$. Studies have been conducted using biomechanical analysis, computational or not, with the purpose of selecting an appropriate system that provides maximum stability and minimum trauma during their insertion ${ }^{14}$. In this context, the objective of the present study was to perform a systematic review of the literature about the main methodologies used in the biomechanical evaluation of fixation systems using titanium plates in mandibular condyle fractures.

\section{Methods}

The following electronic databases were used without restriction concerning to date of publication: PubMed, EMBASE, LILACS and MEDLINE. The search strategy used terms or combinations exemplified in Table 1 with restriction to English, Spanish and Portuguese languages. After this action, two reviewers (MFB and FWGC) independently evaluated the titles and abstracts of the selected articles (Table 1).
TABLE 1 - Search strategies for electronic databases.

\begin{tabular}{|c|c|c|}
\hline N. & Expression & Total \\
\hline 1 & Mandibular fractures & 5216 \\
\hline 2 & Maxilomandibular fractures & 1033 \\
\hline 3 & Mandibular condyle & 7062 \\
\hline 4 & Biomechanics & 65942 \\
\hline 5 & Mandibular fractures and mandibular condyle & 1196 \\
\hline 6 & $\begin{array}{l}\text { Biomechanics and mandibular fractures and } \\
\text { mandibular condyle }\end{array}$ & 26 \\
\hline 7 & Maxilomandibular fractures and biomechanics & 5 \\
\hline 8 & Mandibular condyle and biomechanics & 212 \\
\hline 9 & Finite element analysis & 5658 \\
\hline 10 & Mandibular fractures and finite element analysis & 35 \\
\hline 11 & Mandibular condyle and finite element analysis & 36 \\
\hline 12 & $\begin{array}{l}\text { Mandibular fractures and mandibular condyle and } \\
\text { finite element analysis }\end{array}$ & 7 \\
\hline 13 & $\begin{array}{c}\text { Mandibular condyle and biomechanics and finite } \\
\text { element analysis }\end{array}$ & 16 \\
\hline
\end{tabular}

The adopted inclusion criteria were: studies involving mandibular condyle fractures, studies using titanium plates, biomechanical, in vitro and computational studies involving the finite element method (FEM). Studies in animals, research involving other anatomical sites, studies using non biomechanical methods, analysis of biodegradable materials or osteosynthesis systems that were not titanium plates, case reports, literature reviews and articles written in language not compatible with the search strategy adopted in this work were excluded. Data were organized into two groups (G1: non computational biomechanical studies, G2: computational biomechanical studies) being analyzed and properly interpreted.

\section{Results}

Between 1999 and 2010, 11 articles that met the eligibility criteria listed above were selected, including seven articles involving in vitro studies and four studies involving biomechanical analysis using FEM (Table 2). 
TABLE 2 - Description of selected studies.

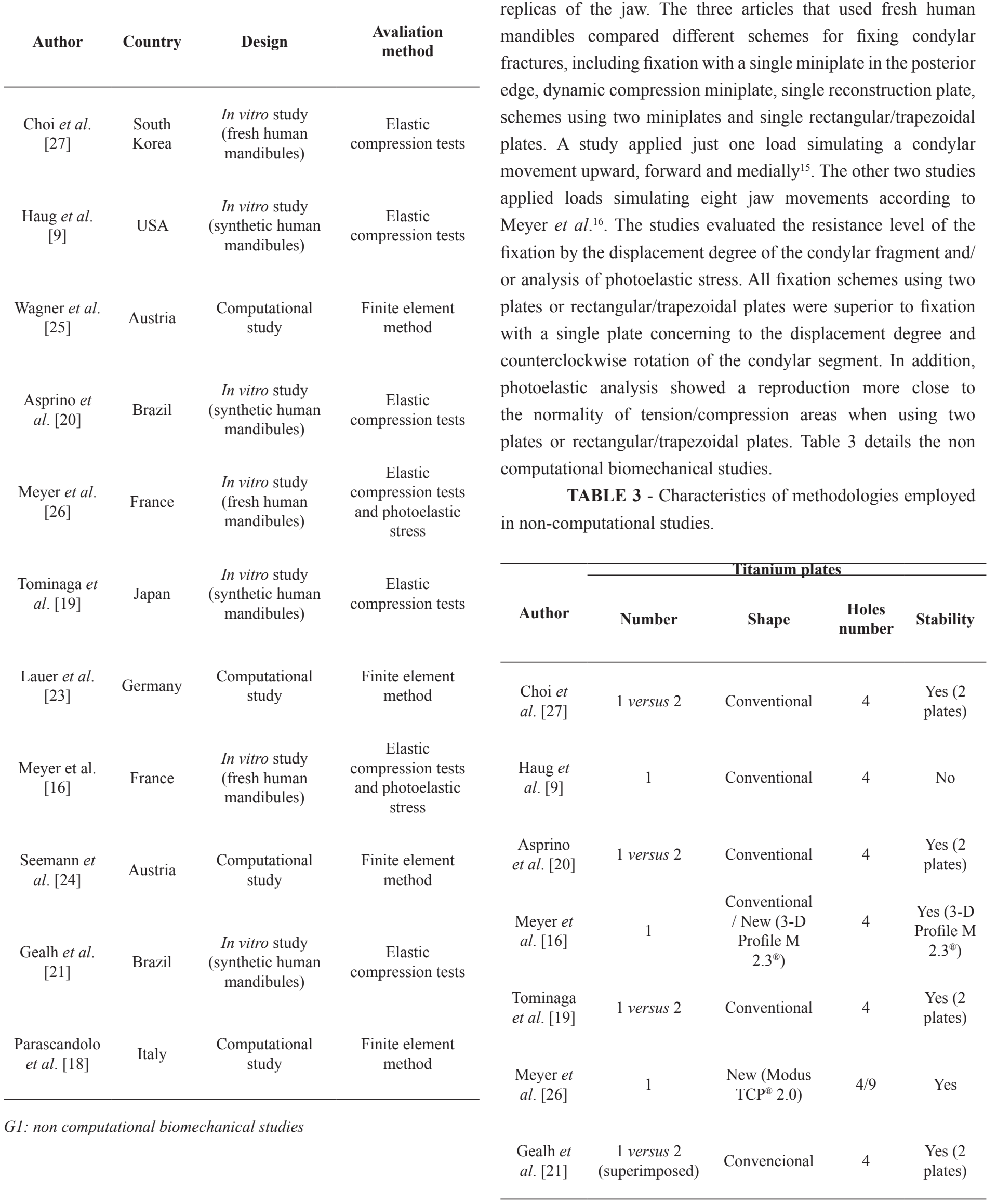

Between the seven in vitro selected studies, three used jaws obtained from human cadavers and four studied polyurethane replicas of the jaw. The three articles that used fresh human mandibles compared different schemes for fixing condylar fractures, including fixation with a single miniplate in the posterior edge, dynamic compression miniplate, single reconstruction plate, plates. A study applied just one load simulating a condylar movement upward, forward and medially ${ }^{15}$. The other two studies applied loads simulating eight jaw movements according to . 
The four studies that assessed the resistance of the fixation systems in polyurethane mandible replicas also used various schemes of plates/screws and evaluation methods. The fixation methods varied from two plates positioned on the anterior and posterior edge of the condyle, two overlapping plates, a single lag screw, a single dynamic compression plate, one against two plates with different lengths of screws and one plate from the lock system. Two studies applied forces directed to condyle from medial to lateral and from anterior to posterior. One study added force from lateral to medial of the condyle. Another study used the method described by Ziccardi et al. ${ }^{15}$ with load simulating a condylar movement upward, forward and medially. All works that used two plates apart showed that this fixation scheme is superior to others. One result showed that two plates overlapping one another was not superior to the model using two plates apart. When only one plate is used, the dynamic compression system is superior to the non-compressive and to the lock system. Additionally, when clinically it is not possible to insert two plates, a biomechanical study showed that longer and bicortical screws can provide increased resistance to fractured segments.

\section{G2: computational biomechanical studies}

Between the four selected studies, two used only one technique testing one 1 union element (one plate), and the other two studies compared two protocols (one versus two union elements). Three studies used union elements simulating plates with four holes, while one study used plates with six holes. Regarding the geometry of the computationally simulated plate, two articles tested plates with new designs (trapezoidal), while the others reproduced conventional plates with straight format. All works applied simulations using muscle loads, although only two articles have explained them. In one study, mandible was subjected to six muscle forces, while in other study, four muscle forces were applied. The distribution of stress lines was prevalent around the screw area (three studies). Research involving the test of only one union element considered it suitable for regular use, while the studies comparing different protocols showed greater stability when affixing two plates. Table 4 details the main findings of the listed articles.
TABLE 4 - Characteristics of methods used in computational studies.

\begin{tabular}{|c|c|c|c|c|}
\hline \multirow{2}{*}{ Author } & \multicolumn{4}{|c|}{ Union element } \\
\hline & Number & Shape & $\begin{array}{c}\text { Holes } \\
\text { number }\end{array}$ & $\begin{array}{c}\text { Stress } \\
\text { distribution }\end{array}$ \\
\hline $\begin{array}{c}\text { Wagner et al. } \\
{[25]}\end{array}$ & $\begin{array}{c}1 \text { versus } \\
2\end{array}$ & Conventional & $4 / 6$ & $\begin{array}{l}\text { Around the } \\
\text { screw area }\end{array}$ \\
\hline $\begin{array}{l}\text { Lauer et al. } \\
\qquad[23]\end{array}$ & 1 & $\begin{array}{c}\text { New (Modus } \\
\left.\operatorname{TCP}^{\circledR} 2.0\right)\end{array}$ & 4 & $\begin{array}{l}\text { Around the } \\
\text { screw area }\end{array}$ \\
\hline $\begin{array}{c}\text { Seemann et } \\
\text { al. [24] }\end{array}$ & 1 & $\begin{array}{c}\text { New (Modus } \\
\operatorname{TCP}^{\circledR} 1.0 \text { ) }\end{array}$ & 4 & Plate center \\
\hline $\begin{array}{l}\text { Parascandolo } \\
\text { et al. }[18]\end{array}$ & $\begin{array}{c}1 \text { versus } \\
2\end{array}$ & Conventional & 4 & $\begin{array}{l}\text { Around the } \\
\text { screw area }\end{array}$ \\
\hline
\end{tabular}

\section{Discussion}

The accuracy about the fractured bone reduction and the fixation stability have been considered as important prerequisites for the function restoration in situations of injury to the mandibular condyle $^{7}$. It is recognized that the temporomandibular joint is subject to loads from various muscle groups that are active during the masticatory efforts ${ }^{17}$. Thus, the fixation methods should have sufficient resistance to oppose these forces and these methods can not interfere with the condyle position after reduction. Several types of laboratory methods have been described in the literature to assess the efficacy of fixation schemes in relation to functional loads experienced by the mandibular condyle ${ }^{16,18,21}$. There is still no consensus about the optimal fixation method for condylar process fractures ${ }^{19}$. The research mainly use jaws from fresh human cadavers ${ }^{16,26,27}$, polyurethane replica of mandibles ${ }^{19-22}$ and, recently, finite element methods ${ }^{18,23-25}$.

\section{Non computational biomechanical studies}

Biomechanical studies in the treatment of condylar fractures help in the knowledge about how the various osteosynthesis systems behave in the face of forces and loads experienced by the temporomandibular joint (TMJ). Due to the unique feature of $\mathrm{TMJ}$ regarding to the distribution of tension and compression zones after masticatory efforts, their fixing principles differ from the other regions of the jaw. During chewing efforts in the first molars and incisors regions, compression zones are generated in the region of the condyle posterior border and tension 
areas next to the ramus superior border (mandibular notch) ${ }^{26}$.

Considering the principles of functionally stable fixation of Champy, osteosynthesis should be performed in tension areas to counteract the trend of opening the fracture line. This explains the poor primary stability of most schemes that used only one plate on the ramus posterior border. Even stronger or two superimposed plates (lock, dynamic compression or reconstruction) can fail or break when used alone ${ }^{27}$. The main reason for this is that even they have been more robust plates, they are not positioned in the correct anatomical site to support the physiological forces.

The simulation methods of the muscle forces must also be taken into account in the critical analysis of the biomechanical studies results. Two reviewed articles simulated only the loads experienced in the joint when occurs the maximum bite force ${ }^{15,19,27}$. These two articles found that two plates presented greater resistance to permanent deformation than the methods of a single plate (reconstruction, dynamic compression, miniplate) $(p<0.05)$. Additionally, the authors found that the use of a dynamic compression miniplate provides good stability to the condylar segment between all single plate schemes. Three studies simulated lateral and medial loads to condyle ${ }^{20-22}$. In these studies, almost all single fixing schemes suffered small deformations when subjected to loads similar to masticatory forces. Haug et al. ${ }^{22}$ proved that the dynamic compression plates were more favorable to counter the latero-lateral moves of the mandibular condyle. Asprino et al. ${ }^{20}$ suggest the use of two plates, but when it is not possible due to the segment size or surgical difficulty, the single plate should be fixed with longer screws $(8 \mathrm{~mm})$. Gealh et al. ${ }^{21}$ proved that two overlapping plates do not increase the resistance of the condyle to the lateral loads.

Only two articles studied the use of synthetic materials specifically designed for use in condylar fractures ${ }^{16,26}$. These plates (four and nine holes) designed in a trapezoidal shape showed better results than the use of a single plate or lag screws when forces simulating the various masticatory muscles were generated in the fixed condyle. The authors advocate the use of these specific fixing schemes saying that these plates meet the principles of the functionally stable fixation in condylar region and are able to resist the physiological forces.

\section{Computational biomechanical studies}

The computational biomechanical studies employ a conventional method for obtaining virtual prototypes, based on a real jaw surface, which is reproduced by the finite element method, taking into consideration the anisotropic typical properties of the jawbone ${ }^{18,23-25}$.
In order to obtain an experimental model using finite elements is necessary to define initially the geometry of the structure to be analyzed. Lauer et al. ${ }^{23}$ and Parascandolo et al. ${ }^{18}$ reproduced plates on an artificial model of the human mandible, while Wagner et al. ${ }^{25}$ used computed tomography images to create the virtual model, based on the conversion of the Hounsfield values in elastic hardness values. Then the object is graphically drawn using a specific computer program for, then discretize (split) the created structure in small elements (finite) in specific software, which will form a two or three dimensional mesh of them. The next step is to determine the mechanical and physical properties of each constituent of the model. Parascandolo et al. ${ }^{18}$ developed their virtual model of the mandible based on physical (Poisson's coefficient $0.34 \mathrm{Mpa}$ ) and mechanical (950Mpa tensile load; 970Mpa compression load; 880Mpa yield stress, 113.800 Young's modulus) specific properties, different from other authors who have not specified. Finally, after determining all the properties, the application of needed loads and results analysis are performed. Wagner et al. ${ }^{25}$ tested less muscle groups compared to the work of Parascandolo et al. ${ }^{18}$. However, the first authors applied proportionately more muscular forces, especially the temporal muscle (42.4\%).

Studies that used the finite element method have also attempted to determine an effective and stable osteosynthesis protocol for condylar fractures. However, only two studies conducted comparative tests between the use of a single plate and the use of two appositional plates at the fracture site ${ }^{18,25}$. Both studies found that the protocol involving two plates was the most appropriate, indicating it as a method of choice. However, Lauer et al. ${ }^{23}$ and Seemann et al. ${ }^{24}$, when using the technique of a single plate, observed satisfactory results in terms of stability. Probably this fact had happened because they tested new plates with favorable formats. These authors performed clinical studies with these plates and no fracture cases were found.

\section{Conclusions}

Although few studies have used the finite element method, the results of in vitro studies are similar in some ways, to those found in computational studies, regarding the use of two stable titanium miniplates in such fractures. In addition, future clinical trials, applying the methodology with finite elements or not, are necessary to better indicate the most appropriate technique for osteosynthesis in cases of mandibular condyle fractures. 


\section{References}

1. Gassner R, Tuli T, Hächl O, Rudisch A, Ulmer H. Craniomaxillofacial trauma: a 10 year review of 9,543 cases with 21,067 injuries. J Craniomaxillofac Surg. 2003;31(1):51-61.

2. Oikarinen KS. Clinical management of injuries to the maxilla, mandible, and alveolus. Dent Clin North Am. 1995;39(1):113-31.

3. Zachariades N, Mezitis M, Mourouzis C, Papadakis D, Spanou A. Fractures of the mandibular condyle: a review of 466 cases. Literature review, reflections on treatment and proposals. J Craniomaxillofac Surg. 2006;34(7):421-32.

4. Chalya PL, McHembe M, Mabula JB, Kanumba ES, Gilyoma JM. Etiological spectrum, injury characteristics and treatment outcome of maxillofacial injuries in a Tanzanian teaching hospital. J Trauma Manag Outcomes. 2011;5(1):7.

5. Bhagol A, Singh V, Kumar I, Verma A. Prospective evaluation of a new classification system for the management of mandibular subcondylar fractures. J Oral Maxillofac Surg. 2011;69(4):1159-65.

6. Villarreal PM, Monje F, Junquera LM, Mateo J, Morillo AJ, González C. Mandibular condyle fractures: determinants of treatment and outcome. J Oral Maxillofac Surg. 2004;62(2):155-63.

7. Singh V, Bhagol A, Goel M, Kumar I, Verma A. Outcomes of open versus closed treatment of mandibular subcondylar fractures: a prospective randomized study. J Oral Maxillofac Surg. 2010;68(6):1304-9.

8. Danda AK, Muthusekhar MR, Narayanan V, Baig MF, Siddareddi A. Open versus closed treatment of unilateral subcondylar and condylar neck fractures: a prospective, randomized clinical study. J Oral Maxillofac Surg. 2010;68(6):1238-41.

9. Haug RH, Assael LA. Outcomes of open versus closed treatment of mandibular subcondylar fractures. J Oral Maxillofac Surg. 2001;59(4):370-5; discussion 375-6.

10. Jensen T, Jensen J, Norholt SE, Dahl M, Lenk-Hansen L, Svensson P. Open reduction and rigid internal fixation of mandibular condylar fractures by an intraoral approach: a long-term follow-up study of 15 patients. J Oral Maxillofac Surg. 2006;64(12):1771-9.

11. Schneider M, Erasmus F, Gerlach KL, Kuhlisch E, Loukota RA, Rasse M, Schubert J, Terheyden H, Eckelt U. Open reduction and internal fixation versus closed treatment and mandibulomaxillary fixation of fractures of the mandibular condylar process: a randomized, prospective, multicenter study with special evaluation of fracture level. J Oral Maxillofac Surg. 2008;66(12):2537-44.

12. Worsaae N, Thorn JJ. Surgical versus nonsurgical treatment of unilateral dislocated low subcondylar fractures: a clinical study of 52 cases. J Oral Maxillofac Surg. 1994;52(4):353-60; discussion 360-1.

13. Yang WG, Chen CT, Tsay PK, Chen YR. Functional results of unilateral mandibular condylar process fractures after open and closed treatment. J Trauma. 2002;52(3):498-503.

14. Pilling E, Eckelt U, Loukota R, Schneider K, Stadlinger B. Comparative evaluation of ten different condylar base fracture osteosynthesis techniques. Br J Oral Maxillofac Surg. 2010;48(7):527-31

15. Ziccardi VB, Schneider RE, Kummer FJ. Wurzburg lag screw plate versus four-hole miniplate for the treatment of condylar process fractures. J Oral Maxillofac Surg. 1997;55(6):602-7.

16. Meyer C, Martin E, Kahn JL, Zink S. Development and biomechanical testing of a new osteosynthesis plate (TCP) designed to stabilize mandibular condyle fractures. J Craniomaxillofac Surg. 2007;35(2):84-90.

17. Ellis III E, Throckmorton GS. Treatment of mandibular condylar process fractures: biological considerations. J Oral Maxillofac Surg. 2005;63(1):115-34.
18. Parascandolo S, Spinzia A, Parascandolo S, Piombino P, Califano L. Two load sharing plates fixation in mandibular condylar fractures: biomechanical basis. J Craniomaxillofac Surg. 2010;38(5):385-90.

19. Tominaga K, Habu M, Khanal A, Mimori Y, Yoshioka I, Fukuda J. Biomechanical evaluation of different types of rigid internal fixation techniques for subcondylar fractures. J Oral Maxillofac Surg. 2006;64(10):1510-6.

20. Asprino L, Consani S, de Moraes M. A comparative biomechanical evaluation of mandibular condyle fracture plating techniques. J Oral Maxillofac Surg. 2006;64(3):452-6.

21. Gealh WC, Costa JV, Ferreira GM, Iwaki Filho L. Comparative study of the mechanical resistance of 2 separate plates and 2 overlaid plates used in the fixation of the mandibular condyle: an in vitro study. J Oral Maxillofac Surg. 2009;67(4):738-43.

22. Haug RH, Peterson GP, Goltz M. A biomechanical evaluation of mandibular condyle fracture plating techniques. J Oral Maxillofac Surg. 2002;60(1):73-80

23. Lauer G, Pradel W, Schneider M, Eckelt U. A new 3-dimensional plate for transoral endoscopic-assisted osteosynthesis of condylar neck fractures. J Oral Maxillofac Surg. 2007;65(5):964-71.

24. Seemann R, Schicho K, Reichwein A, Eisenmenger G, Ewers R, Wagner A. Clinical evaluation of mechanically optimized plates for the treatment of condylar process fractures. Oral Surg Oral Med Oral Pathol Oral Radiol Endod. 2007;104(6):1-4.

25. Wagner A, Krach W, Schicho K, Undt G, Ploder O, Ewers R. A 3-dimensional finite-element analysis investigating the biomechanical behavior of the mandible and plate osteosynthesis in cases of fractures of the condylar process. Oral Surg Oral Med Oral Pathol Oral Radiol Endod. 2002;94(6):678-86.

26. Meyer C, Serhir L, Boutemi P. Experimental evaluation of three osteosynthesis devices used for stabilizing condylar fractures of the mandible. J Craniomaxillofac Surg. 2006;34(3):173-81.

27. Choi BH, Kim KN, Kim HJ, Kim MK. Evaluation of condylar neck fracture plating techniques. J Craniomaxillofac Surg. 1999;27(2):109-12.

28. Choi BH, Yi CK, Yoo JH. Evaluation of condylar neck fracture plating techniques. J Oral Maxillofac Surg. 2001;59(7):734-7.

\section{Correspondence:}

Fábio Wildson Gurgel Costa

Rua João Sorongo, 1016/205

60416-000 Fortaleza - CE Brasil

Tel.: (55-85)8819-1364

fwildson@yahoo.com.br

Received: January 11, 2012

Review: March 14, 2012

Accepted: April 16, 2012

Conflict of interest: none

Financial source: none

${ }^{1}$ Research performed at School of Dentistry, Postgraduate Program in Dentistry, Dental Clinic Area, Federal University of Ceara (UFC), Fortaleza-CE, Brazil. 